Vol. 16 (2007): 199-211

\title{
Optimal share contracts between pig producers
}

\author{
Karin Larsén, Per Skargren, Carl Johan Lagerkvist, Hans Andersson \\ The Swedish University of Agricultural Sciences, Department of Economics, PO Box 7013, \\ SE-750 07 Uppsala, Sweden, email: karin.larsen@ekon.slu.se
}

\begin{abstract}
This paper analyses the economic benefits from vertical coordination in pig production (i.e. a contract between a specialised piglet and a specialised fattening pig producer) using a static model of a share contract. An empirical illustration is presented for Swedish pig producers considering the impact of growth rates, feed conversion efficiency and mortality rates. Moreover, the variation in pig prices and the biological variation in the growth rates of pigs are considered. Producers are assumed to be risk averse and the risk aversion concept is elaborated by obtaining the producers "desired confidence level" that corresponds to a given risk aversion coefficient. The results suggest that there exists a range of Pareto efficient share allocations. Potential gains in expected utility from vertical coordination compared to independent production are about $25 \%$ for both categories of producers.
\end{abstract}

Key-words: Pig production, risk sharing

\section{Introduction}

The number of pig producers in Sweden has decreased substantially in the last decades: from 26 000 in the year of 1980 to 2800 in 2005 (Statistics Sweden 2006). At the same time, specialisation in pig production has increased. Vertically coordinated and specialised production systems are the two major forms of pig production in Sweden today (30 and
$50 \%$ of the total Swedish pig production respectively according to Swedish Meats 2007). Specialised pig production includes piglet production and fattening pig production.

A specialised piglet producer either markets the piglets to a piglet-delivery organisation or directly to a fattening pig producer. Correspondingly, a specialised fattening pig producer either buys the piglets from a piglet-delivering organisation or 
Larsén, K. et al. Optimal share contracts between pig producers

directly from a piglet producer. An advantage of engaging a delivery organisation is that the pig producer is not obliged to sell/buy piglets at a specific date that is regulated by a contract. However, there is a risk that the fattening pig producer does not get access to piglets at the optimal point in time. Correspondingly, the piglet producer might not be able to sell piglets at the optimal market weight.

A partnership arrangement between a piglet and a fattening pig producer in the form of a share contract, where all revenues and costs are shared among the two producers, may be a measure of reducing the price risk for both categories of producers. Historical Swedish price data show substantial variation in prices of piglets which implies uncertainty for the fattening pig producer (when purchasing piglets) as well as for the piglet producer (when selling piglets). Figures 1 and 2 display the variation of price and gross margin for representative piglet and fattening pig producers in Sweden during the period 1998-2005. However, in a share contract arrangement, where the piglets are delivered directly to the fattening pig producer instead of engaging a piglet delivery organisation, the only product price risk that both producers face (and share) is the payment for fattening pigs.

Another important factor motivating the development of contractual arrangements is that pigs in vertically coordinated production systems where the piglets are age-segregated, display positive health effects (Holmgren and Lundeheim 2002). Field experiments suggest that pigs in vertically coordinated production systems have, on average, higher daily growth rate and improved feed conversion efficiency compared to pigs that are acquired in the spot market (Andersson 1997). They are also characterized by a lower mortality rate and an improved growth rate. Hence, a larger number of batches may be produced every year. The improved production results in vertically coordinated production systems may be attributable to the fact that the pigs originate from the same herd and therefore are less exposed to the risk of diseases (Holmgren and Lundeheim 2002).

Consequently, there are several potential benefits, including improved production results and price risk reduction, of forming a contractual ar- rangement between a specialised piglet producer and a specialised fattening pig producer. These forms of contractual arrangements have become increasingly common and today constitute 20\% of the pig production in Sweden (Swedish Meats 2006).

Different aspects of production contracts between a principal (e.g. processor) and one or several agents (e.g. producers) have been widely analyzed in the literature (e.g. Leegomonochai and Vukina 2005, Dubois and Vukina 2004, Levy and Vukina

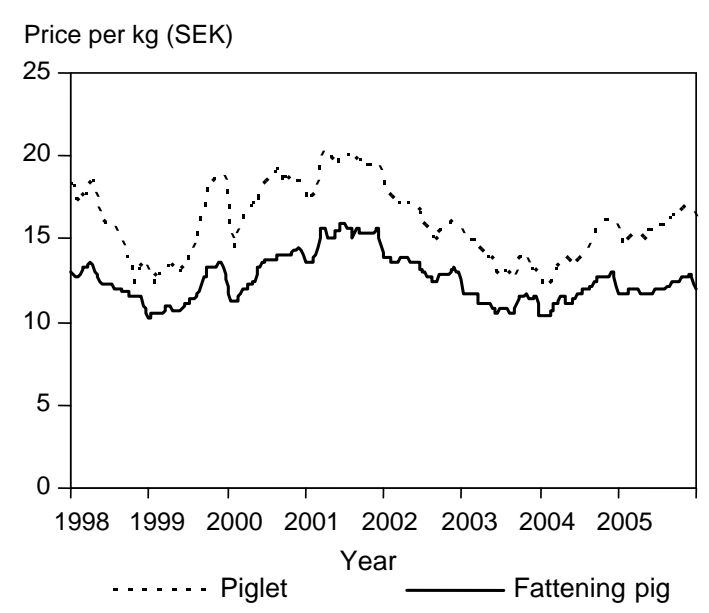

Fig. 1. Variation in piglet and fattening pig prices 1998-2005.

Contribution gross margin (SEK per pig)

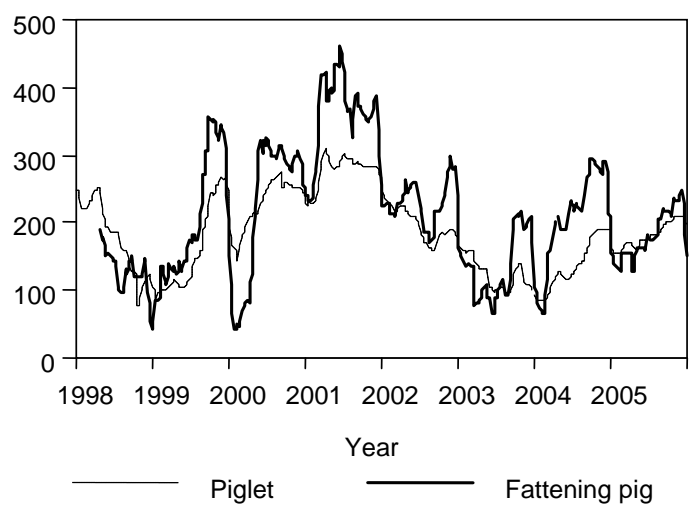

Fig. 2. Variation in contribution gross margin for piglet and fattening pig producers. 
Vol. 16 (2007): 199-211

2002 and 2004). However, to our knowledge, less attention has been given to profit sharing in vertical contracts between producers such as contracts between a piglet and fattening pig producer. Pietola and Wang (2000) evaluate contracts in the form of price- and quantity-fixing agreements for piglets for pig producers in Finland. The authors used an option approach and found that the value of a contract was positive for both farrowing and finishing units. For the case of farrowing units, Boger (2001) analyzed marketing arrangements among Polish pig producers and buyers.

The objective of this study is to analyse the incentives for forming a partnership arrangement between a producer specialised in piglet production and a producer specialised in fattening pigs using a static theoretical model of a share contract. The model is based on the share contract model suggested by Petersson and Andersson (1996) in order to study rental partnership arrangements. However, adjustments have been made to the model in order to apply to the case of vertically co-integrated pig producers. The model considers the stochastic growth of piglets and fattening pigs; the variance of pig prices and the improved production results due to vertically coordinated production. A novel part of our work is to account for biological and technological incentives as well as the explicit and implicit dependencies between random variables in developing the variance measures. Accurate modelling of random dependences is vital for obtaining proper measurements of partnership incentives. The reason is that the total variance of profits obtained by each partner also affects the optimal sharing ratio, as well as the individual rationality constraints for the partners respectively. Notwithstanding, the potential importance of other random elements in pig production, the random variables included in the study are generally of major importance to the economic outcome of pig production systems. Another important contribution in relation to the to existing literature is that we consider the economic value of the improved production results as a result attributable to biological effects in addition to the reduction of income uncertainty. Furthermore, we determine the relative effects of these factors on the potential utility gains associated with a share con- tract between vertically coordinated producers.

The study also elaborates on the risk aversion concept and demonstrates how a producers "desired confidence level" that corresponds to a given risk aversion coefficient can be calculated using the so-called Katoaka's criterion (Katoaka 1965). The criterion suggests a method to account for risk without having to make a specific assumption about the producer's level of risk aversion by instead using "desired confidence levels". Hence, the purpose is to provide a risk aversion measure that (a) has more straightforward interpretation than the measures derived from expected utility theory, and (b) does not rely on elicited risk aversion coefficients. The elicitation is by itself known to contribute towards potential biases (Just and Pope 2003).

The model is applied to empirical data for Swedish pig producers. The core of Pareto efficient arrangements that satisfy the individual rationality restriction are derived by varying the welfare weights for various levels of risk aversion. Subsequently, estimates of potential utility gains for a piglet and a fattening pig producer that enter a vertically coordinated contract arrangement are obtained. It is demonstrated that potential utility gains compared to the alternative of no contractual arrangement (i.e. independent production by each producer, respectively) from a partnership arrangement are substantial: $25.4 \%$ for the piglet producer and $25.0 \%$ for the fattening pig producer.

\section{Theoretical model}

In this section, the expected utilities of the piglet producer and the fattening pig producer given independent production are specified. Thereafter, a static model of a share contract between a piglet producer and a fattening pig producer is developed. The model is restricted for producers that are currently active as independent pig producers as the producers are assumed to already have incurred fixed costs (investments in buildings). Prices and daily growth of piglets and fattening pigs are assumed to be stochastic while all other variables are assumed to be deterministic. 
Larsén, K. et al. Optimal share contracts between pig producers

The producers' utility functions are assumed to be constant absolute risk aversion (CARA) functions. An appealing feature of the CARA function is the applicability in decision analysis (Hardaker et. al. 1998). Moreover, Lien and Hardaker (2001) found that the choice of utility function had a minor effect on the results in a study of Norwegian farms. The net revenue of the producers is expressed per pig and we make the simplifying assumption that the production period at the fattening pig producer remains the same irrespective if he participates in a share contract or is producing independently. Consequently, the weight of the slaughtered pig is slightly higher in the case of a share contract.

\section{Piglet and fattening pig producers utility given independent production}

The expected net revenue of the piglet producer per pig produced, given independent production, is assumed to be

$$
\begin{aligned}
& E\left(\pi^{p}\left(P_{p}, G_{p}, t_{p}, I, F_{p}, E_{p}, D_{p}, F_{b}, R\right)\right) \\
& =E\left(P_{p}\right) \cdot E\left(G_{p}\right) \cdot t_{p}+I-F_{p} \cdot E_{p} \cdot E\left(G_{p}\right) \cdot t_{p} \\
& -D_{p} \cdot t_{p}-F_{b}-R
\end{aligned}
$$

where

$P_{p}$ : payment that the piglet producer receives per kg when he sells the piglets, where $P_{p} \sim N\left(\overline{\mathrm{P}}_{\mathrm{p}}, \sigma_{\mathrm{G}_{\mathrm{p}}}^{2}\right)$

$G_{p}$ : daily growth rate of a piglet, where $G_{p} \sim N \quad\left(\overline{\mathrm{G}}_{\mathrm{p}}, \sigma_{\mathrm{G}_{\mathrm{p}}}^{2}\right)$

$t_{p}$ : the production period for piglets

$F_{p}:$ price of feed for piglets per $\mathrm{kg}$

$E_{p}$ : conversion feed efficiency of the piglet $(\mathrm{kg}$ feed per kg growth)

I : revenue for the slaughter sow per piglet produced

$F_{b}$ : average daily price of feed for a breedingsow per piglet

$\mathrm{R}$ : livestock replacement cost per litter

$D_{p}$ : various daily costs per pig
The expected net revenue of the fattening pig producer per pig produced, $\pi^{f}$, is defined by (2)

$$
\begin{aligned}
& E\left(\pi^{f}\left(P_{f}, Q, P_{p}, G_{p}, G_{f}, t_{p}, t_{f}, F_{f}, E_{f}, D_{f}\right)\right) \\
& =E\left(P_{f}\right) \cdot Q \cdot\left(E\left(G_{p}\right) \cdot t_{p}+E\left(G_{f}\right) \cdot t_{f}\right)- \\
& P_{p} \cdot E\left(G_{p}\right) \cdot t_{p}-F_{f} \cdot E_{f} \cdot E\left(G_{f}\right) \cdot t_{f}-D_{f} \cdot t_{f}
\end{aligned}
$$

where

$P_{f}$ : $\quad$ payment the piglet producer receives per $\mathrm{kg}$ when the $\mathrm{f}_{\mathrm{i}}$ :ening pigs are marketed, where $P_{f} \sim N, \mathrm{~N}\left(\overline{\mathrm{P}}_{\mathrm{f}}, \sigma_{\mathrm{P}_{\mathrm{f}}}^{2}\right)$

$G_{f}$ : daily growth rate of a fattening pig, where $G_{f} \sim N, \mathrm{~N}\left(\overline{\mathrm{G}}_{\mathrm{f}}, \sigma_{\mathrm{G}_{\mathrm{f}}}^{2}\right)$

$t_{f}$ : $\quad$ the production period for fattening pigs

$Q$ : $\quad$ ratio between slaughtered weight and the live weight

$F_{f}: \quad$ price of feed per $\mathrm{kg}$

$E_{f}$ : conversion feed efficiency of the fattening pig ( $\mathrm{kg}$ feed per $\mathrm{kg}$ growth)

$D_{f}$ : $\quad$ various daily costs per fattening pig

The variance of the piglet and fattening pig producers' net revenues, $\operatorname{Var}\left(\pi^{p}\right)$ and $\operatorname{Var}\left(\pi^{f}\right)$, are derived in Appendix I. Assuming that the expected utility of the piglet producer and the fattening pig producer respectively can be represented by a CARA utility function, the utility of producer $i$ is given by

$$
E\left(U^{i}\left(\pi^{i}\right)\right)=\pi^{i}-\frac{\varphi_{i}}{2} \cdot \operatorname{Var}\left(\pi^{i}\right)
$$

where $\varphi_{i}$ is the coefficient of absolute risk aversion of producer $i$ and $i=$ piglet producer, fattening pig producer.

\section{A static model of a share contract between a piglet and a fattening pig producer}

When calculating the total net revenue per pig given a contractual arrangement, we account for the improvement in production results in vertically coordinated pig production. The improved production results that are considered are: higher growth rate, improved feed conversion efficiency and lower mortality. The economic gain of lower mortality is 
Vol. 16 (2007): 199-211

incorporated in the model as an increment of average profit per pig, denoted by $m$. The growth rate and conversion efficiency given vertically coordinated production are denoted by the index ei. The total net revenue per pig given vertically coordinated production is then defined by (6).

$$
\begin{aligned}
& E\left(\pi^{\top}\right)=t_{p}\left(E\left(P_{f}\right) \cdot Q-F_{p} \cdot E\left(E_{p}^{e}\right)\right) E\left(G_{p}^{e j}\right) \\
& +t_{f}\left(E\left(P_{f}\right) \cdot Q-F_{f} \cdot E\left(E_{f}^{e}\right)\right) E\left(G_{f}^{e}\right)+C
\end{aligned}
$$

where

$$
C=I-D_{p} \cdot t_{p}-F_{b}-R-D_{f} \cdot t_{f}+m
$$

The variance of the total net revenue per pig given vertically coordinated production, $\operatorname{Var}\left(\pi^{T}\right)$, is derived in Appendix I.

The model of share allocation developed is similar to the one used by Petersson and Andersson (1996), who analyse a share contract between a landlord and a crop farmer. The idea of a share contract is that each agent (in this case a piglet producer and a fattening pig producer) receives a share of the total revenues and pays a share of the total costs. We make the simplifying assumption that the share of revenues equals the share of costs for each producer (Eswaran and Kotwal 1985, Petersson and Andersson 1996). The share of revenues and costs of the piglet producer is denoted by $S_{p}$ and the share of revenues and costs of the fattening pig producer is denoted by $S_{f}$, where $S_{p}=$ $1-S_{f}$ and $S_{p} \in[0,1]$. The objective function is a weighed sum of the producers' expected utilities. The welfare weights, $\alpha_{p}$ and $\alpha_{f}$, reflect the bargaining power of the producers, where $\alpha_{p}+\alpha_{f}=1$ and $a_{i} \in[0,1]$ (Varian 1992). The maximisation problem is thus stated

$$
\begin{aligned}
& \underset{S_{p}}{\operatorname{Maximise} \alpha_{p}} \cdot\left[S_{p} \cdot \pi^{\top}-\frac{1}{2} \cdot \varphi_{p} \cdot S_{p}^{2} \cdot \operatorname{Var}\left(\pi^{\top}\right)\right]+ \\
& \alpha_{f} \cdot\left[\left(1-S_{p}\right) \cdot \pi^{\top}-\frac{1}{2} \cdot \varphi_{f} \cdot\left(1-S_{p}\right)^{2} \cdot \operatorname{Var}\left(\pi^{\top}\right)\right]
\end{aligned}
$$

subject to the constraint

$$
0 \leq \mathrm{S}_{\mathrm{p}} \leq 1
$$

The Kuhn-Tucker condition is given by

$$
\begin{aligned}
& \frac{\delta L}{\delta S_{p}}=\alpha_{p} \cdot\left[\pi^{\top}-\varphi_{p} \cdot S_{p}^{*} \cdot \operatorname{Var}\left(\pi^{\top}\right)\right]+ \\
& \alpha_{f} \cdot\left[-\pi^{\top}+\varphi_{f} \cdot\left(1-S_{p}^{*}\right) \cdot \operatorname{Var}\left(\pi^{\top}\right)\right]-\lambda_{1}+\lambda_{2}=0
\end{aligned}
$$

where * denotes the optimal solution for $S_{p}$.

(11) implies that the optimal sharing ratio of the piglet producer, assuming that the constraints on $\mathrm{S}_{\mathrm{p}}$ are non-binding $\left(\lambda_{1}=0\right.$ and $\left.\lambda_{2}=0\right)$ then $\mathrm{S}_{\mathrm{p}}{ }^{*}$ is given by (12)

$$
S_{p}^{*}=\frac{\left(\alpha_{p}-\alpha_{f}\right) \cdot \pi^{\top}}{\left(\alpha_{p} \cdot \varphi_{p}+\alpha_{f} \cdot \varphi_{f}\right) \cdot \operatorname{Var}\left(\pi^{\top}\right)}+\frac{\alpha_{f} \cdot \varphi_{f}}{\left(\alpha_{p} \cdot \varphi_{p}+\alpha_{f} \cdot \varphi_{f}\right)}
$$

implying that the optimal sharing ratio of the fattening pig producer is $S_{f}{ }^{*}=1-S_{p}{ }^{*}$.

The second component of the right hand side of (12) is unique for risk sharing between two agents who are assumed to have CARA utility functions (Shah and Thakor 1988, Petersson and Andersson 1996).

For the individual rationality restriction to hold for each producer, the core of Pareto efficient contracts must satisfy (Pauly 1967)

$$
\mathrm{S}_{i}^{*} \cdot \pi^{\top}-\frac{1}{2} \cdot \varphi_{i} \cdot \mathrm{S}_{\mathrm{i}}^{* 2} \cdot \operatorname{Var}\left(\pi^{\top}\right) \geq \pi^{\mathrm{i}}-\frac{\varphi_{\mathrm{i}}}{2} \cdot \operatorname{Var}\left(\pi^{\mathrm{i}}\right) \forall \mathrm{i}
$$

where $i=$ piglet producer, fattening pig producer. (13) implies that the utility of each producer must be at least as large given a contractual arrangement as in the case of independent production.

\section{Elaboration on risk aversion measures in empirical models}

According to the model specified in (9), the producers are assumed to be risk averse and their risk preferences are considered by specifying their expected utilities as CARA functions. In general, the more concave the utility function is, the higher is the producer's risk aversion. The degree of concavity in this case is determined by the magnitude of the coefficient of absolute risk aversion. Hence, a value of the coefficient of absolute risk aversion to be used in the empirical analysis must be determined.

The difficulties of eliciting a decision maker's risk aversion are well known and attempts to es- 
Larsén, K. et al. Optimal share contracts between pig producers

timate farmers' risk aversion coefficients have been made (see for example Raskin and Cochran (1986) for an overview of some commonly used risk aversion coefficients). Moreover, the application of expected utility theory to explain agricultural decision maker's behavior in the presence of risk has been criticized because it assumes that risk preferences are solely defined by the curvature of the utility function. Other aspects also ought to influence the observed behavior of a producer such as human capital, as argued by Just and Pope (2003). Furthermore, various constraints such as fixed allocated inputs and the risk of bankruptcy also should be considered (Just and Peterson 2003). Estimates of risk aversion coefficients obtained when these aspects are not considered will be biased.

The relation between the absolute risk aversion, $r_{a}(\pi)$, and the relative risk aversion, $r_{r}(\pi)$, for a given level of transitory income, $\pi$, is $r_{a}(\pi)$ $=r_{r}(\pi) / \pi$. Thus, for given levels of the coefficient of relative risk aversion and transitory income, the corresponding coefficient of absolute risk aversion can be obtained. Andersson and Dillon (1992) suggest the following scale for the degree of relative risk aversion:

$r_{r}(W)=0.5$ : hardly risk averse at all;

$r_{r}(W)=1.0$ : somewhat risk averse (normal);

$r_{r}(W)=2.0$ : rather risk averse;

$r_{r}(W)=3.0$ : very risk averse;

$r_{r}(W)=4.0$ : almost paranoid about risk.

It should be noted that the scale above applies to wealth, $W$, and not transitory income, $\pi$. In this study, we make the assumption that the wealth of a pig producer equals his/her income. Thus, we obtain a producer's coefficient of absolute risk aversion by dividing the coefficient of relative risk aversion by the producer's income. Contract curves corresponding to a coefficient of relative risk aversion of 0.5 (hardly risk averse at all), 1.0 (somewhat risk averse) and 2.0 (rather risk averse) will be calculated.

In the remaining part of this section, we demonstrate how Katoaka's criterion (Katoaka 1963) may be used to provide additional understanding of the impact of producers risk attitudes by interpreting risk aversion as a "desired confidence level" of the producer. The coefficient of absolute risk aver- sion can then be used to calculate a corresponding confidence level of the producer. This provides a more straight-forward way to interpret the level of risk aversion.

An approximation of the risk premium (RP) using a second order Taylor expansion of a decision maker's utility function, $U(\pi)$, following van Kooten et. al (1997) yields

$\mathrm{RP}=\frac{1}{2} \cdot \sigma_{\pi}^{2} \cdot \varphi$

where $\pi$ is net income, $\sigma_{\pi}^{2}$, is the variance of the net income and

$\varphi_{i}=-\left(U^{\prime \prime}(\pi) / U^{\prime}(\pi)\right)$ is the Arrow-Pratt measure of absolute risk aversion. Equation (14) is equivalent to the expression used for the risk premium in the producers' utility functions in (3) and (5).

In order to apply Katoaka's criterion, the risk premium is written as (van Kooten et al. 1997)

$\mathrm{RP}=\mathrm{Z}_{1-\alpha} \cdot \sigma_{\pi}$

where $(1-\alpha)$ is the decision maker's desired confidence level and $\mathrm{Z}_{1-\alpha}$ is a statistic corresponding to a one-tailed confidence interval for the appropriate probability distribution. Given the assumption of normality of $\pi, Z_{1-\alpha}$ is a proxy for the one-tailed $t$ value. For example, $Z$ equals 0 for a decision maker with a desired confidence level of $50 \%$, i.e. a risk neutral decision maker, and 2.576 for a decision maker with a desired confidence level of $99.5 \%$.

By combining (14) and (15), we obtain an expression for a coefficient of absolute risk aversion that corresponds to a given confidence level. The confidence level that corresponds to a given level of the coefficient of absolute risk aversion is found by solving for $Z_{1-\alpha}$.

$\varphi_{\mathrm{i}}=\frac{2 \cdot \mathrm{Z}_{1-\alpha}}{\sigma_{\pi}} \Leftrightarrow \mathrm{Z}_{1-\alpha}=\frac{\varphi_{\mathrm{i}} \cdot \sigma_{\pi}}{2}$

In the study we assume that $\pi$ is normally distributed and the desired confidence levels that correspond to a relative risk aversion of $0.5,1$ and 2 (from the Andersson and Dillon scale) are calculated. The "confidence level approach" reveals a more straightforward interpretation of the coefficient of absolute risk aversion since it simply reflects the 
desired confidence level of the producer. An estimate of $Z_{1-\alpha}$, and indirectly the desired confidence level of producer $i$, is thus obtained as

$$
\mathrm{Z}_{(1-\alpha)_{i}}=\frac{\varphi_{\mathrm{i}} \cdot \sqrt{\operatorname{Var}\left(\pi^{\mathrm{i}}\right)}}{2}
$$

where $\varphi_{i}=0.5,1$ and 2 and $\pi^{\mathrm{i}}$ is the profit of farmer $i$.

\section{Data}

The model is solved using data reflecting the average condition for Swedish piglet and fattening pig producers (Table 1). Estimates of improved production results in vertically coordinated pig production compared to independent production are obtained from Andersson (1997). Weekly spot market prices for piglets $(27 \mathrm{~kg})$ and fattening pigs (approximately $85-90 \mathrm{~kg}, 58 \%$ meat content) are available for the

Table 1. Variables used in the empirical application (SEK = Swedish kronor, 2005 monetary values).

\begin{tabular}{|c|c|c|c|}
\hline Variable & Description & Unit & Value \\
\hline $\mathrm{P}_{\mathrm{p}}$ & Price for piglets $(27 \mathrm{~kg})^{\dagger \ddagger}$ & SEK per kg & 16.7 \\
\hline $\mathrm{G}_{\mathrm{p}}$ & Growth of piglet & kg per day & 0.39 \\
\hline I & Revenue from slaughtering sow ${ }^{\dagger}$ & SEK & 23.4 \\
\hline $\mathrm{F}_{\mathrm{p}}$ & Price of feed for piglet per $\mathrm{kg}^{\dagger}$ & SEK & 2.10 \\
\hline$E_{p}$ & Conversion efficiency of piglet & $\mathrm{kg}$ feed per kg growth & 3.17 \\
\hline$D_{p}$ & Various daily expenses per piglet ${ }^{\dagger}$ & SEK & 0.29 \\
\hline $\mathrm{F}_{\mathrm{b}}^{\mathrm{p}}$ & Price of feed for breeding-sow per piglet ${ }^{\dagger}$ & SEK & 27.9 \\
\hline $\mathrm{R}$ & Livestock replacement cost per pig ${ }^{\dagger}$ & SEK & 47.3 \\
\hline$P_{f}$ & $\begin{array}{l}\text { Price for fattening pig ( } 85 \mathrm{~kg}, 58 \% \text { meat content) including esti- } \\
\text { mated delivery bonus for an average fattening pig producers }{ }^{\dagger \ddagger}\end{array}$ & SEK per $\mathrm{kg}$ & 12.6 \\
\hline Q & Ratio between slaughter weight and live weight & - & 0.73 \\
\hline $\mathrm{G}_{\mathrm{f}}$ & Growth of fattening pig given independent production & kg per day & 0.86 \\
\hline $\mathrm{G}_{\mathrm{f}}^{\mathrm{ei}}$ & Growth of fattening pig given external integration & kg per day & 0.89 \\
\hline $\mathrm{F}_{\mathrm{f}}$ & Price of feed for fattening pig ${ }^{\dagger}$ & SEKper kg & 1.65 \\
\hline $\mathrm{E}_{\mathrm{f}}$ & $\begin{array}{l}\text { Conversion efficiency of fattening pig given independent } \\
\text { production }\end{array}$ & $\mathrm{kg}$ feed per $\mathrm{kg}$ growth & 2.78 \\
\hline $\mathrm{E}_{\mathrm{f}}^{\mathrm{ei}}$ & Conversion efficiency of fattening pig given external integration & $\mathrm{kg}$ feed per $\mathrm{kg}$ growth & 2.75 \\
\hline$D_{f}$ & Various daily expenses per fattening pig $^{\dagger}$ & SEK & 0.32 \\
\hline $\operatorname{Std}\left(G_{p}\right)$ & Standard deviation for growth rate of piglets* & $\mathrm{kg}$ & 0.12 \\
\hline $\operatorname{Std}\left(G_{f}\right)$ & Standard deviation for growth rate of fattening pigs* & $\mathrm{kg}$ & 0.09 \\
\hline $\operatorname{Cov}\left(\mathrm{G}_{\mathrm{p}}, \mathrm{G}_{\mathrm{f}}\right)$ & Covariance between growth rate of piglets and fattening pigs* & $\mathrm{kg}$ & 0 \\
\hline $\operatorname{Std}\left(P_{p}\right)$ & Standard deviation for price of piglets & SEK & 2.20 \\
\hline $\operatorname{Std}\left(\mathrm{P}_{\mathrm{f}}\right)$ & Standard deviation for price of fattening pigs ${ }^{\dagger \ddagger}$ & SEK & 1.42 \\
\hline $\operatorname{Cov}\left(\mathrm{P}_{\mathrm{p}}, \mathrm{P}_{\mathrm{f}}\right)$ & Covariance for price of piglets and fattening pigs $\mathrm{s}^{\dagger \neq}$ & SEK & 2.88 \\
\hline
\end{tabular}

${ }^{\dagger}$ Average for the years 1998-2005.

‡ Calculated using weekly data for prices for the time period 1998-2005 (Swedish Meats for 1999-2005, a weighted average of prices for Skanek, Farmek and Scan Norrland for 1998).

*The estimate of the standard error in the growth rate of piglets was provided from PIG-Skara, Sweden, and the estimate of the standard error in the growth rate of fattening pigs was obtained from field experiments conducted at the Swedish University of Agricultural Sciences. 


\section{AGRICULTURAL AND FOOD SCIENCE}

\section{Larsén, K. et al. Optimal share contracts between pig producers}

time period $1998-2005^{1}$ and is used to calculate expected values, standard deviations and covariances of piglet and hog prices. Estimates of delivery bonuses for an average producer in Sweden are added to the price of hogs. All other prices represent annual averages for the time period 1998-2005. The standard deviation in the growth rates is assumed to be the same irrespective of vertically coordinated production or independent production $(0.39 \mathrm{~kg}$ per day for piglets and $0.86 \mathrm{~kg}$ per day for fattening pigs). The correlation between the growth rate of piglets and fattening pigs is assumed to be 0 in the base scenario but we test for the robustness of this assumption. All remaining data were obtained from the database Agriwise (2007) at the Swedish University of Agricultural Sciences.

The number of days in piglet production, $t_{p}$, is assumed to be 70 . The expected weight of the piglets when they are delivered to the fattening pig producer/ piglet-delivering organisation at a daily growth rate of $0.39 \mathrm{~kg}$ is approximately $27 \mathrm{~kg}$. The model in this study restricts the production period for the fattening pig production to be the same in vertically coordinated production as in independent production despite the fact that fattening pigs grow faster in vertically coordinated production. The number of days in fattening pig production, $t_{f}$, is assumed to be 110 and the expected slaughter weight is approximately 89 $\mathrm{kg}$ given independent production (the ratio between slaughter weight and live weight is 0,73 ). Since the pigs in vertically coordinated system display a higher average daily growth rate, they reach a higher average weight after 110 days. The producers may receive a slightly lower payment per kg pig meat for pigs with a high slaughter weight. However, in this study we make the simplifying assumption that producers in external integration receive the same payment per $\mathrm{kg}$ despite a somewhat higher slaughter weight.

The mortality of pigs in vertically coordinated production systems is $0.2 \%$ less than compared to independent producers (Andersson 1997). The economic gain of lower mortality is calculated as 0.002 times the producers' total net revenues given independent production.

1 A weighted average of prices for Skanek, Farmek and Scan Norrland for 1998 and Swedish Meats for the years 1999-2005.

\section{Results}

The contract curves, i.e. the core of Pareto efficient partnership arrangements, are obtained by varying the welfare weights for various levels of risk aversion and imposing the individual rationality constraint (Equation 13). Moreover, the potential gains in expected utility of each producer are calculated as well as the share of the gains that is attributable to risk reduction.

The core of the Pareto efficient contracts that satisfy the individual rationality restriction, assuming an equal confidence level of the producers, is illustrated in Figure 3.

As can be noted from Table 2, the welfare weight intervals for which Pareto efficient contracts exist represent a rather short range: they range between 0.004 (coefficient of risk aversion $=0.5,56.8 \%$ confidence level) and 0.058 (coefficient of risk aversion $=2,75.3 \%$ confidence level). The corresponding intervals for the contract shares range between $6.8 \%$ and $20.3 \%$.

The welfare weights can be interpreted as each producer's bargaining power relative to the other producer. Hence, a welfare weight of 0.5 of both producers implies that they have equally strong

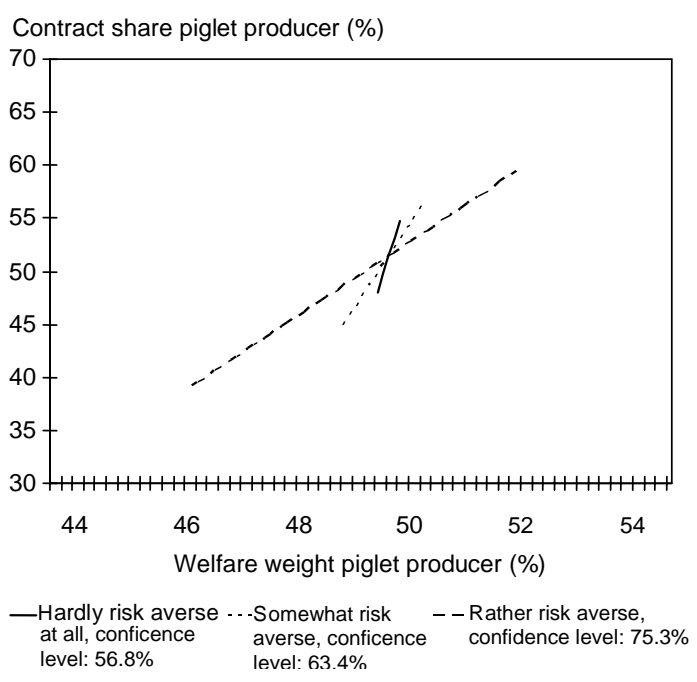

Fig. 3. Core of Pareto efficient contracts. 
Vol. 16 (2007): 199-211

Table 2. Intervals for welfare weights (bargaining power) and contract shares.

\begin{tabular}{cccccc}
\hline $\begin{array}{c}\text { Coefficient of rela- } \\
\text { tive risk aversion of } \\
\text { producers }\end{array}$ & $\begin{array}{c}\text { Corresponding } \\
\text { confidence level, } \\
\%\end{array}$ & $\begin{array}{c}\text { Length of pareto } \\
\text { efficient, welfare } \\
\text { weight interval }\end{array}$ & $\begin{array}{c}\text { Length of pareto ef- } \\
\text { ficient, share contract } \\
\text { interval, \% }\end{array}$ & $\begin{array}{c}\text { Contract share, } \\
\text { piglet producer, } \\
\%\end{array}$ & $\begin{array}{c}\text { Welfare } \\
\text { weight, piglet } \\
\text { producer }\end{array}$ \\
\hline 0.5 & 56.80 & 0.004 & 6.80 & $48.0-54.8$ & $0.498-0.502$ \\
1 & 63.40 & 0.014 & 11.20 & $45.0-56.2$ & $0.492-0.506$ \\
2 & 75.30 & 0.058 & 20.30 & $39.1-59.5$ & $0.465-0.523$ \\
\hline
\end{tabular}

bargaining power. Since the welfare weights are close to 0.5 for all Pareto efficient contracts, this suggests share contracts may only be implemented between producers who are characterized by approximately equally strong bargaining power.

The potential gains in expected utility of each producer given a share contract are substantial: $25.4 \%$ for the piglet producer and $25.0 \%$ for the fattening pig producer 2 . By potential utility gain we refer to the level of the producers utility in the case when the other producer is indifferent between participating in a share contract and producing independently. This is the case when the other producer's individual rationality restriction (Equation 13 ) is satisfied with equality. The money metric equivalent is approximately 45 SEK for both producers. The utility gains are a result of two effects: the improved production results in a vertically coordinated production and risk reduction. The share of the utility gain that is attributable to risk reduction is $28.6 \%$ for the piglet producer and $12.2 \%$ for the fattening pig producer. These shares are calculated as the difference between the risk premium when operating independently and the risk premium in a share contract divided by the increase in expected utility. The utility gain from risk reduction may be partly explained by risk sharing. Apart from the

2 The results do not change substantially when the assumption of zero correlation between the growth rates of the piglets and the fattening pigs is relaxed. A correlation coefficient of 0.6 implies a 24.1 per cent potential utility gain for the piglet producer (compared to 25.4 when the correlation is assumed to be zero). The potential utility gain for the fattening pig producer was 24.9 (compared to 25.0 when the correlation is assumed to be zero). The span of the welfare weight interval did not change. risk sharing effect, there are some additional factors that affect the variance of each producers share of the net revenue in presence of a share contract. For example, stochastic growth and the producer price of piglets causes an uncertainty in the revenue that the piglet producer receives when he sells the piglets to a piglet delivering organisation. A stochastic price of piglets is also a source of risk for the fattening pig producer when he buys piglets. Given the existence of a share contract in a vertically coordinated system, these sources of risk are mitigated.

\section{Summary and conclusions}

The objective of this paper was to analyse whether there exist incentives for establishing a partnership arrangement, using a share contract, between producers specialised in piglet production and fattening pig production. A theoretical model of a share contract was developed and applied to data representing Swedish pig production.

The variance in piglet and fattening pig prices and the growth rates of piglets and fattening pigs were accounted for in the model. Moreover, improved production results in vertically coordinated pig production (higher growth rate, improved conversion efficiency and lower mortality) were taken into account. The theoretical model assumes that the producers are risk averse and the risk aversion concept was elaborated in the study. A scale of relative risk aversion suggested by Andersson and Dillon (1992) was used in the empirical application, but we also showed how Katoaka's criterion can be 
Larsén, K. et al. Optimal share contracts between pig producers

used to obtain corresponding confidence levels of the producers. The purpose of this approach is to provide a more straight-forward interpretation of a producers risk aversion (as it simply can be interpreted as a producers "desired confidence level") and does not rely on elicited values of risk aversion coefficients.

The results suggest that substantial incentives for a share contract between a piglet and a fattening pig producer exists, although within a rather short interval of the welfare weights. It is demonstrated that the potential utility gains are substantial: $25.4 \%$ for the piglet producer and $25.0 \%$ for the fattening pig producer at a relative risk aversion of 1 (corresponding to a confidence level of $63.4 \%$ ). The share of increase in utility that is due to risk reduction is $12.2 \%$ for the fattening pig producer and even slightly higher, $28.6 \%$, for the piglet pig producer. The span of the contract curves increase with increasing risk aversion. Thus, our study suggests that the gains attributable to improved production results and risk reduction are substantial in the presence of a share contract arrangement between piglet and fattening pig producers in Sweden. It should also be noted that the potential utility gains are mainly a result of the improved production results in vertically coordinated production. Although the price risk is significant, the results are dominated by the production data.

Finally, it should be mentioned that there are other advantages of vertically coordinated pig production systems except for those considered in this analysis. One implication of the higher growth rate is that pigs in vertically co-integrated production can be delivered to slaughter at a younger age. The number of days that the fattening pig producer keeps the pigs is therefore reduced compared to when he buys the piglets in the spot market. Hence, a larger number of batches per year may be produced. For this benefit to materialise, it requires that the piglet producer is sufficiently large in order to be able to supply a new batch of piglets at the required date of time. Moreover, it has been demonstrated that contracts between piglet producers and fattening pig producer imply a more efficient use of stables ${ }^{3}$. This might be explained by the fact that fattening pig producers that have a contract with a piglet producer are guaranteed to be able to buy piglets even at times when there is an excess demand for piglets. Thus, the gains of a contract arrangement between a piglet and a fattening pig producer may be even higher relative to those obtained in this analysis.

\section{Appendix}

\section{Derivation of variance expressions}

It is assumed that prices and daily growth rates of piglets and fattening pigs are stochastic while all other variables are deterministic. When calculating the variance expressions, it is necessary to make assumptions about the dependency between the stochastic variables. We assume that there is no dependency between prices and growth rates. Furthermore, we assume that there is a non-zero coefficient of correlation between piglet and fattening pig prices and between growth rates between piglets and fattening pigs (the latter correlation is however assumed to be zero in the base scenario).

The variance expressions are calculated using the following results

$$
\begin{aligned}
& V(U)=\sum_{i=1}^{n} a_{1}^{2} V\left(Y_{i}\right)+2 \sum_{i<j} \sum a_{i} a_{j} \operatorname{Cov}\left(Y_{i}, Y_{j}\right) \\
& V(Z)=E\left(Z^{2}\right)-(E(Z))^{2} \\
& V(X Y)=V(X) V(Y)+V(X) E(Y)^{2}+E(X)^{2} V(Y)
\end{aligned}
$$

(X and $\mathrm{Y}$ are independent $)^{4}$

3 Pietola and Wang (2000) estimate the value for efficient flow scheduling using an option value approach.

4 Equation (9) in Bohrnstedt and Goldberger (1969). 


\section{Variance of net return of piglet producer when} operating independently

The net return of the piglet producer when he/she is operating independently is

$\pi^{\mathrm{p}}=\mathrm{aP}_{\mathrm{p}} \mathrm{G}_{\mathrm{p}}+\mathrm{bG}_{\mathrm{p}}+\mathrm{M}$

where

$\mathrm{a}=\mathrm{t}_{\mathrm{p}}$

$\mathrm{b}=-\mathrm{F}_{\mathrm{p}} \mathrm{E}_{\mathrm{p}} \mathrm{t}_{\mathrm{p}}$

$M=I-D_{p} t_{p}-F_{b}-R$

The expected net return is

$E\left(\pi^{p}\right)=a E\left(P_{p}\right) E\left(G_{p}\right)+b E\left(G_{p}\right)+M$

The variance of the net return is

$\operatorname{Var}\left(\pi^{\mathrm{p}}\right)=\operatorname{Var}\left(\mathrm{aP}_{\mathrm{p}} \mathrm{G}_{\mathrm{p}}+\mathrm{bG}_{\mathrm{p}}\right)=$

$a^{2} \operatorname{Var}\left(P_{p} G_{p}\right)+b^{2} \operatorname{Var}\left(G_{p}\right)+2 a b C \operatorname{ov}\left(P_{p} G_{p}, G_{p}\right)$

where

$\operatorname{Var}\left(P_{p} G_{p}\right)=V\left(P_{p}\right) V\left(G_{p}\right)$

$+V\left(P_{p}\right) E\left(G_{p}\right)^{2}+E\left(P_{p}\right)^{2} V\left(G_{p}\right)$

and

$\operatorname{Cov}\left(P_{p} G_{p}, G_{p}\right)=E\left(P_{p} G_{p}^{2}\right)-E\left(P_{p} G_{p}\right) E\left(G_{p}\right)=$

$E\left(P_{p}\right) E\left(G_{p}^{2}\right)-E\left(P_{p}\right) E\left(G_{p}\right)^{2}=E\left(P_{p}\right)\left[\operatorname{Var}\left(G_{p}\right)\right]$

Variance of net return of fattening pig producer when operating independently

The net return of the fattening pig producer when operating independently is ${ }^{5}$

$\pi^{f}=\mathrm{aP}_{\mathrm{f}}+\mathrm{bP}_{\mathrm{f}} \mathrm{G}_{\mathrm{f}}+\mathrm{CP}_{\mathrm{p}}+\mathrm{dG}_{\mathrm{f}}+\mathrm{N}$

where

$\mathrm{a}=\mathrm{QG}_{\mathrm{p}} \mathrm{t}_{\mathrm{p}}$

$\mathrm{b}=\mathrm{Qt}_{\mathrm{f}}$

$\mathrm{C}=-\mathrm{G}_{\mathrm{p}} \mathrm{t}_{\mathrm{p}}$

$\mathrm{d}=-\mathrm{F}_{\mathrm{f}} \mathrm{E}_{\mathrm{f}} \mathrm{t}$

$N=-D_{f} t_{f}$

The expected net return is

\footnotetext{
5 Note that the growth of the piglet is assumed to be deterministic when the fattening pig producer operates independently.
}

$E\left(\pi^{f}\right)=a E\left(P_{f}\right)+b E\left(P_{f} G_{f}\right)$

$+C E\left(P_{p}\right)+d E\left(G_{f}\right)+N$

The variance of the net return is

$\operatorname{Var}\left(\pi^{\mathrm{f}}\right)=\operatorname{Var}\left(\mathrm{aP}_{\mathrm{f}}+\mathrm{bP}_{\mathrm{f}} \mathrm{G}_{\mathrm{f}}+\mathrm{CP}_{\mathrm{p}}+\mathrm{dG}_{\mathrm{f}}\right)=$

$=a^{2} \operatorname{Var}\left(P_{f}\right)+b^{2} \operatorname{Var}\left(P_{f} G_{f}\right)+c^{2} \operatorname{Var}\left(P_{p}\right)$

$+d^{2}\left(G_{f}\right)+2 \operatorname{abCov}\left(P_{f}, P_{f} G_{f}\right)+\operatorname{2acCov}\left(P_{f}, P_{p}\right)$

$+2 b c \operatorname{Cov}\left(P_{f} G_{f}, P_{p}\right)+2 b d \operatorname{Cov}\left(P_{f} G_{f}, G_{f}\right)$

where

$\operatorname{Var}\left(P_{f} G_{f}\right)=V\left(P_{f}\right) V\left(G_{f}\right)+V\left(P_{f}\right) E\left(G_{f}\right)^{2}$

$+E\left(P_{f}\right)^{2} V\left(G_{f}\right)$

$\operatorname{Cov}\left(P_{f}, P_{f} G_{f}\right)=E\left(P_{f}^{2} G_{f}\right)-E\left(P_{f}\right) E\left(P_{f} G_{f}\right)=$

$E\left(P_{f}^{2}\right) E\left(G_{f}\right)-E\left(P_{f}\right)^{2} E\left(G_{f}\right)=$

$E\left(G_{f}\right)\left[\operatorname{Var}\left(P_{f}^{2}\right)\right]$

$\operatorname{Cov}\left(P_{f} G_{f}, P_{p}\right)=E\left(P_{f} P_{p} G_{f}\right)-E\left(P_{f} G_{f}\right) E\left(P_{p}\right)=$

$E\left(P_{f} P_{p}\right) E\left(G_{f}\right)-E\left(P_{f}\right) E\left(G_{f}\right) E\left(P_{p}\right)=$

$E\left(G_{f}\right)\left[\operatorname{Cov}\left(P_{f} P_{p}\right)\right]$

and

$\operatorname{Cov}\left(P_{f} G_{f}, G_{f}\right)=E\left(P_{f} G_{f}^{2}\right)-E\left(P_{f} G_{f}\right) E\left(G_{f}\right)$

$E\left(P_{f}\right) E\left(G_{f}^{2}\right)-E\left(P_{f}\right) E\left(G_{f}\right)^{2}=$

$=E\left(P_{f}\right)\left[\operatorname{Var}\left(G_{f}\right)\right]$

Variance of net return in the case of a share contract

The net return in the share contract case is

$$
\begin{aligned}
& \pi^{\top}=\mathrm{aP}_{\mathrm{f}} \mathrm{G}_{\mathrm{p}}+\mathrm{bG}_{\mathrm{p}}+\mathrm{CP}_{\mathrm{f}} \mathrm{G}_{\mathrm{f}}+\mathrm{dG}_{\mathrm{f}}+\mathrm{C} \\
& \text { where } \\
& \mathrm{a}=\mathrm{Qt} \mathrm{t}_{\mathrm{p}} \\
& \mathrm{b}=-\mathrm{F}_{\mathrm{p}} \mathrm{E}_{\mathrm{p}} \mathrm{t}_{\mathrm{p}} \\
& \mathrm{C}=\mathrm{Qt}_{\mathrm{f}} \\
& \mathrm{d}=-\mathrm{F}_{\mathrm{f}} \mathrm{E}_{\mathrm{f}} \mathrm{t}_{\mathrm{f}} \\
& \mathrm{C}=\mathrm{I}-\mathrm{D}_{\mathrm{p}} \cdot \mathrm{t}_{\mathrm{p}}-\mathrm{F}_{\mathrm{b}}-\mathrm{R}-\mathrm{D}_{\mathrm{f}} \cdot \mathrm{t}_{\mathrm{f}}
\end{aligned}
$$




\section{AGRICULTURAL AND FOOD SCIENCE}

Larsén, K. et al. Optimal share contracts between pig producers

The expected net return is

$$
\begin{aligned}
& E\left(\pi^{\top}\right)=a E\left(P_{f}\right) E\left(G_{p}\right)+b E\left(G_{p}\right) \\
& +C E\left(P_{f}\right) E\left(G_{f}\right)+d E\left(G_{f}\right)+C
\end{aligned}
$$

The variance of the net return is

$$
\begin{aligned}
& \operatorname{Var}\left(\pi^{\top}\right)=\operatorname{Var}\left(a_{f} G_{p}+b G_{p}+c_{f} G_{f}+d G_{f}\right)= \\
& =a^{2} \operatorname{Var}\left(P_{f} G_{p}\right)+b^{2} \operatorname{Var}\left(G_{p}\right)+c^{2} \operatorname{Var}\left(P_{f} G_{f}\right) \\
& +d \operatorname{Var}\left(G_{f}\right)+\operatorname{2abCov}\left(P_{f} G_{p}, G_{p}\right)+2 a c C o v \\
& \left(P_{f} G_{p}, P_{f} G_{f}\right)+\operatorname{2adCov}\left(P_{f} G_{p}, G_{f}\right)+2 b c \operatorname{Cov} \\
& \left(G_{p}, P_{f} G_{f}\right)+2 \operatorname{bdCov}\left(G_{p}, G_{f}\right)+2 \operatorname{cdCov}\left(P_{f} G_{f}, G_{f}\right)
\end{aligned}
$$

where

$$
\begin{aligned}
& \operatorname{Var}\left(P_{f} G_{p}\right)=V\left(P_{f}\right) V\left(G_{p}\right)+V\left(P_{f}\right) E\left(G_{p}\right)^{2} \\
& +E\left(P_{f}\right)^{2} V\left(G_{p}\right) \\
& \operatorname{Var}\left(P_{f} G_{f}\right)=V\left(P_{f}\right) V\left(G_{f}\right)+V\left(P_{f}\right) E\left(G_{f}\right)^{2} \\
& +E\left(P_{f}\right)^{2} V\left(G_{f}\right) \\
& \operatorname{Cov}\left(P_{f} G_{p}, G_{p}\right)=E\left(P_{f} G_{p}^{2}\right)-E\left(P_{f} G_{p}\right) E\left(G_{p}\right)= \\
& E\left(P_{f}\right) E\left(G_{p}^{2}\right)-E\left(P_{f}\right) E\left(G_{p}\right)^{2}=E\left(P_{f}\right)\left[\operatorname{Var}\left(G_{p}\right)\right] \\
& \operatorname{Cov}\left(P_{f} G_{p}, P_{f} G_{f}\right)=E\left(P_{f}^{2} G_{p} G_{f}\right)-E\left(P_{f} G_{p}\right) E\left(P_{f} G_{f}\right)= \\
& E\left(P_{f}^{2}\right) E\left(G_{p} G_{f}\right)-E\left(P_{f}\right)^{2} E\left(G_{p}\right) E\left(G_{f}\right)= \\
& {\left[\operatorname{Var}\left(P_{f}\right)+E\left(P_{f}\right)^{2}\right]\left[\operatorname{Cov}\left(G_{p} G_{f}\right)+E\left(G_{p}\right) E\left(G_{f}\right)\right]} \\
& -E\left(P_{f}\right)^{2} E\left(G_{p}\right) E\left(G_{f}\right)=\operatorname{Var}\left(P_{f}\right) \operatorname{Cov}\left(G_{p} G_{f}\right) \\
& +\operatorname{Var}\left(P_{f}\right) E\left(G_{p}\right) E\left(G_{f}\right)+E\left(P_{f}\right)^{2} \operatorname{Cov}\left(G_{p} G_{f}\right)+ \\
& E\left(P_{f}\right)^{2} E\left(G_{p}\right) E\left(G_{f}\right)-E\left(P_{f}\right)^{2} E\left(G_{p}\right) E\left(G_{f}\right)= \\
& {\left[\operatorname{Var}\left(P_{f}\right)+E\left(P_{f}\right)^{2}\right] \operatorname{Cov}\left(G_{p} G_{f}\right)+\operatorname{Var}\left(P_{f}\right) E\left(G_{p}\right) E\left(G_{f}\right)}
\end{aligned}
$$

$$
\begin{aligned}
& \operatorname{Cov}\left(P_{f} G_{p}, G_{f}\right)=E\left(P_{f} G_{p} G_{f}\right)-E\left(P_{f} G_{p}\right) E\left(G_{f}\right) \\
& =E\left(P_{f}\right) E\left(G_{p}, G_{f}\right)-E\left(P_{f}\right) E\left(G_{p}\right) E\left(G_{f}\right)= \\
& =E\left(P_{f}\right)\left[\operatorname{Cov}\left(G_{p}, G_{f}\right)\right] \\
& \operatorname{Cov}\left(G_{p}, P_{f} G_{f}\right)=E\left(P_{f} G_{p} G_{f}\right)-E\left(G_{p}\right) E\left(P_{f} G_{f}\right) \\
& =E\left(P_{f}\right) E\left(G_{p}, G_{f}\right)-E\left(P_{f}\right) E\left(G_{p}\right) E\left(G_{f}\right)= \\
& =E\left(P_{f}\right)\left[\operatorname{Cov}\left(G_{p}, G_{f}\right)\right]
\end{aligned}
$$

and

$$
\begin{aligned}
& \operatorname{Cov}\left(P_{f} G_{f}, G_{f}\right)=E\left(P_{f} G_{f}^{2}\right)-E\left(P_{f} G_{f}\right) E\left(G_{f}\right) \\
& E\left(P_{f}\right) E\left(G_{f}^{2}\right)-E\left(P_{f}\right) E\left(G_{f}\right)^{2}= \\
& =E\left(P_{f}\right)\left[\operatorname{Var}\left(G_{f}\right)\right]
\end{aligned}
$$

\section{References}

Agriwise 2007. Department of Economics, Swedish University of Agricultural Sciences. Cited: 29 Jan 2007. Available on the internet: www.agriwise.org

Andersson, C. 1997. Externintegrerad svinproduktion. Master Thesis 91. Department of Animal Nutrition and Management, Swedish University of Agricultural Sciences, Uppsala, 1-32.

Andersson, J.J. and Dillon, J.L. 1992. Risk Analysis in Dryland Farming Systems. Farming Systems Management Series No 2, FAO, Rome.

Boger, S. 2001. Quality and contractual choice: a transaction cost approach to the Polish hog market. European Review of Agricultural Economics 28(3): 241-261.

Bohrnstedt, G.W., and Goldberger, A.S. 1969. On the exact covariance of products of random numbers. Journal of the American Statistical Association 64: 1439-1442.

Eswaran, M. and Kotwal, A. 1985. A theory of contractual structure in agriculture. The American Economic Review 75(3): 352-367.

Hardaker, J.B., Huirne, R.B. M., Anderson, J.R. and Lien G. 1998. Coping with risk in agriculture, second edition. CAB International, Wallingford, $332 \mathrm{pp}$.

Holmgren, N. and Lundeheim, N. 2002. Utveckling av uppfödningsformer och hälsa hos slaktsvin. Svensk veterinärtidning 54: 10, 469-74.

Just, D.R. and Peterson, H.H. 2003. Diminishing Marginal Utility of Wealth and Calibration of Risk in Agriculture. American Journal of Agricultural Economics (5): 1234-1241.

Just, E.J. and Pope, R.D. 2003. Agricultural Risk Analysis: Adequacy of Models, Data and Issues. American Journal of Agricultural Economics (5): 1249-1256.

Katoaka, S. 1963. A stochastic programming model. Econometrica 31(Jan): 181-196.

Levy, A. and Vukina, A. 2002. Optimal Linear Contracts with Heterogeneous Agents. European Review of Agricultural Economics 29(2): 205-217.

Levy, A. and Vukina, A. 2004. The League Composition Effect in Tournaments with Heterogenous Players: an empirical Analysis of Broiler Contracts. Journal of Labour Economics 22(2): 353-77.

Lien, G. and Hardaker, J.B. 2001. Whole-farm programming under uncertainty: impacts of subsidy scheme and utility function on portfolio choice in Norwegian agriculture. European Review of Agricultural Economics 28(1): 17-36.

Pauly, M.V. 1967. Clubs, commonality and the core: An integration of game theory and the theory of public goods. Economica (34): 314-324. 


\section{AGRICULTURAL AND FOOD SCIENCE}

Vol. 16 (2007): 199-211

Petersson, J, and Andersson, H. 1996. The benefits of share contracts: some European results. Journal of Agricultural Economics 47(2): 158-171.

Pietola, K.S and Wang, H.H. 2000. The value of price- and quantity-fixing contracts for piglets in Finland. European Review of Agricultural Economics 27(4), 431-447.

Raskin, R, and Cochran, M.J. 1986. Interpretations and Transformations of Scale for the Pratt-Arrow Absolute Risk Aversion Coefficient: Implications for Generalized Stochastic Dominance. Western Journal of Agricultural Economics, 11(2): 204-210.

Shah, S. and Thakor, A.V. 1988. Private versus public ownership: Investment, ownership distribution, and optimality. The Journal of Finance, XLIII: 41-59.

Statisics Sweden 2001. Yearbook of Agricultural Statistics 2001. SCB, Stocholm.

Swedish Meats 2007. Uppfödningssystem gris. Cited: 29 Jan 2007. Available on the internet: www.swedishmeats.com van Kooten, G.C., Young D.L. and Krautkraemer, J.A. 1997. A safety-first approach to dynamic cropping decisions. European Review of Agricultural Economics 24: 47-63.

van Kooten, G.C., Young D.L. and Krautkraemer, J.A. 1997. A safety-first approach to dynamic cropping decisions. European Review of Agricultural Economics 24: 47-63.

Varian, H. 1992. Microeconomic Analysis, third edition. W.W. Norton \& Company, New York, 506 pp.

Vukina, A. and Dubois, P. 2004. Grower Risk Aversion and the Cost of Moral Hazard in Livestock Production Contracts. American Journal of Agricultural Economics 86(3): 835-41.

Vukina, A. and Leegomonchai, P. 2005. Dynamic Incentives and Agent Discrimination in Broiler Production Tournaments. Journal of Economics and Management Strategy 14(4): 849-77. 